\title{
JUNTAR SABER COM SABER: REFLEXÕES SOBRE O PROGRAMA RESIDÊNCIA DOCENTE
}

\section{JOIN KNOW TO KNOW: REFLECTIONS ON THE TEACHER RESIDENCY PROGRAM}

\author{
RICCl, Cláudia Sapag \\ ricci.clau@gmail.com \\ UFMG - Universidade Federal de Minas Gerais
}

\begin{abstract}
RESUMO Há quase dez anos a Coordenação de Aperfeiçoamento de Pessoal de Nível Superior (Capes) tem, entre as suas atribuições, o fomento à formação inicial e continuada de profissionais da Educação Básica. Vários são os programas organizados para os distintos momentos de formação docente: inicial, continuada e extensão, todos comprometidos com a pesquisa e a divulgação científica. O objetivo deste texto é apresentar reflexões sobre um desses programas: o Programa Residência Docente. Trata-se de um projeto que alia, de um lado, as reflexões acadêmicas e os desafios do cotidiano escolar, propiciando o desenvolvimento profissional num diálogo entre os saberes-fazeres da escola, onde atua o residente, e, de outro, o contexto escolar: Centro Pedagógico da Universidade Federal de Minas Gerais (UFMG).
\end{abstract}

PALAVRAS-CHAVE: Educação básica. Desenvolvimento profissional. Formação docente.

ABSTRACT Almost ten years ago the Coordination of Improvement of Higher Education Personnel (Capes) has among its responsibilities the promotion of initial and continuing professional training in Basic Education. There are several developed programs organized according to the different times of teacher education: initial, continued and extended, committed to research and science communication. The aim of this paper is to present reflections on one of these programs: the Teacher Residency Program. This is a project that combines, on the one hand, academic reflections and challenges of everyday school life, providing professional development in a dialogue between school the knowledge - doings of the school which serves the resident and other educational context: the Centro Pedagógico of Federal University of Minas Gerais (UFMG).

KEYWORDS: Basic Education. Professional development. Teacher education.

\section{INTRODUÇÃO}

Pra lutar pelo direito deles - trabalhador. Digo, de um tipo de reunir, pensar juntos, defender o que é seu, pelo que devia ser. Exemplo assim, como a gente falava, de começar pelas coisas que o povo já sabe, já faz de seu: as ideias, os assuntos. Ciço (BRANDÃO, 1982, p.7-10.) 
Ciço, um lavrador mineiro, em um diálogo sobre educação popular com Carlos Rodrigues Brandão, no início da década de 1980 do século passado, pergunta se é possível articular a vivência com o aprendizado. Apesar do tempo transcorrido, das mudanças ao longo de mais de trinta anos, do contexto específico a que se refere - a possibilidade de ser alfabetizado em idade mais avançada -, as palavras de Ciço revelam identidade com os pressupostos do projeto Residência Docente, desenvolvido pelo Centro Pedagógico da Universidade Federal de Minas Gerais (UFMG). Trata-se de uma perspectiva em que a experiência concreta dos sujeitos da educação fundamenta a compreensão sobre a vida e, então, é tomada como base do processo de aprendizado do ser humano, de se incorporar à humanidade. A formação do professor não seria algo que ocorre externamente à sua percepção. Pelo contrário, o professor é fruto de um posicionamento e de uma reflexão - nem sempre consciente - que faz ao longo de e sobre a sua própria trajetória profissional. Em outras palavras, não há como garantir que situações institucionais de formação conquistem os resultados práticos previamente concebidos se, em seus pressupostos, a experiência dos participantes não for campo de reflexão e diálogo.

Com a promulgação da LEI no 11.502, de 11 de julho de 2007, a Coordenação de Aperfeiçoamento de Pessoal de Nível Superior (CAPES) passa ater, entre as suas atribuições, a de subsidiar o Ministério da Educação na formulação de políticas e no desenvolvimento de atividades de suporte à formação de profissionais do magistério para a Educação Básica. Segundo tal legislação, essa formação deve ocorrer em colaboração com os Estados, os Municípios e o Distrito Federal e exclusivamente mediante convênios com instituições de ensino superior públicas ou privadas. Os principais programas de formação de professores apoiados pela Capes estão agrupados conforme os distintos momentos de formação docente: inicial, continuada e extensão, todos comprometidos com a pesquisa e a divulgação científica, conforme é apresentado no Quadro 1, a seguir:

Quadro 1 - Principais Programas de Formação apoiados pela CAPES

\begin{tabular}{|l|c|}
\hline \multicolumn{1}{|c|}{ Formação Inicial } & Formação em pesquisa \\
\hline $\begin{array}{l}\text { Plano Nacional de Formação dos Professores da Educação Básica- } \\
\text { PARFOR }\end{array}$ & Observatório da Educação \\
\hline
\end{tabular}




\begin{tabular}{|l|l|}
\hline $\begin{array}{l}\text { Programa Institucional de Bolsa de Iniciação à Docência - PIBID } \\
\text { Universidade Aberta do Brasil- UAB } \\
\text { Programas de Licenciaturas Internacionais - PLI } \\
\text { Programa de Consolidação das Licenciaturas - PRODOCÊNCIA }\end{array}$ \\
\hline \multicolumn{1}{|c|}{ Formação Continuada e Extensão } & \\
\hline $\begin{array}{l}\text { Mestrados Profissionais } \\
\text { Novos Talentos }\end{array}$ & \multicolumn{1}{c|}{ Divulgação Científica } \\
Cooperação Internacional para Professores da Educação Básica & e Mostras Científicas \\
Residência Docente & Olimpíadas Científicas \\
Formação associada às Olimpíadas de Matemática e de Química & \\
Rede Nacional de Educação e Ciências & \\
\hline
\end{tabular}

Fonte: CAPES (2013)

No grupo dos programas de formação continuada encontra-se o Residência Docente, projeto piloto desenvolvido no Colégio Pedro II (Rio de Janeiro) e no Centro Pedagógico da Universidade Federal de Minas Gerais (Belo Horizonte), que visa proporcionar, aos professores em exercício na rede pública, diferentes experiências e práticas pedagógicas. Segundo a CAPES, o Programa Residência Docente tem como intenção oferecer

formação continuada, por meio do desenvolvimento de competências docentes in loco, num espaço-tempo educacional que une a escola onde atua $o$ residente e a imersão em contexto escolar de reconhecida excelência, contribuindo, desta forma, para o desenvolvimento profissional do docente e para elevar o padrão de qualidade da Educação Básica. (CAPES, 2013, p. 12)

O objetivo deste texto é apresentar o processo de implementação do Projeto Residência Docente no Centro Pedagógico/UFMG, que visa o desenvolvimento profissional a partir do diálogo entre saberes-fazeres escolares. Para tanto, este texto se organiza em dois momentos: reflexões sobre o conceito de formação docente, que supera a ideia de mero treinamento e a noção de capacitação e, em seguida, o relato da experiência desenvolvida no CP/UFMG, pautado pela articulação entre reflexões acadêmicas e desafios do cotidiano escolar.

\section{TREINAMENTO, CAPACITAÇÃO E FORMAÇÃO DOCENTE: DIFERENTES CONCEPÇÕES E PRÁTICAS}

Eu penso que muita gente vinha ajudar, desde que a gente tivesse como acreditar que era uma coisa que tivesse valia mesmo. Uma que a gente junto pudesse fazer e tirar todo o 
proveito. Pra toda gente saber de novo o que já sabe, mas pensa que não. Parece que nisso tem se segredo que a escola não conhece. Ciço (BRANDÃO, 1982, p. 7-10)

A discussão sobre a formação do professor de Educação Básica destacou-se nas últimas décadas, especialmente, a partir da consideração do espaço escolar como lugar de formulação de conhecimentos específicos, que alguns autores denominaram de "saberes escolares". Fruto de determinada compreensão sobre o desenvolvimento do saber humano, alimentada pelas pesquisas desenvolvidas nos campos da psicologia e neurologia, a formação humana, antes vinculada à capacidade de adaptação do ser humano ao meio sustentada pela ideia de condicionamento reflexivo da Escola Comportamental, foi sendo compreendida como um complexo conjunto de experiências e práticas sociais interpretadas por cada sujeito singular.

Tal interpretação do processo de formação humana revaloriza, como é possível perceber, o cotidiano e a vivência concreta. Moto contínuo, a sala de aula reveste-se, a partir de então, de um novo significado e estatuto pedagógico. De lugar de reprodução de conhecimento, é alçada à condição de lugar de construção de significados e experimentações singulares. $O$ professor é o autor, portanto, das estratégias de aprendizagem, construtor dos dilemas a serem explorados em sala de aula. O mundo acadêmico, enfim, de definidor e lugar de produção do saber reconhecido socialmente, é redefinido como parceiro de jornada das práticas de ensino. Tais pressupostos se distanciam de iniciativas e programas governamentais para a formação docente desenvolvidos no final do século passado.

Na década de 1970, um ambicioso programa de treinamento de professores procurava implantar novos elementos técnico-pedagógicos no ensino público, introduzindo técnicas de estudo dirigido, massificação de conteúdos através de livros didáticos, novos contornos curriculares e conteúdos técnico-profissionalizantes. $\mathrm{O}$ objetivo explícito era massificar habilidades básicas, que consolidariam um contingente de profissionais minimamente capacitados para o ingresso no mercado de trabalho formal, notadamente, industrial, em franco crescimento naquele período em que o país captava, com facilidade, poupança externa para realizar investimentos produtivos. 
Na década de 1980, por seu turno, programas estaduais de capacitação do professorado de Ensino Fundamental procuravam consolidar algumas das reformas educacionais em curso, que eram frutos do processo recente de redemocratização do país. Era o início da mudança, em virtude da alteração de paradigma: da preparação para o mercado de massas para a formação de cidadãos ativos.

Na década de 1990 surgiram centros de formação de professores, tanto em âmbito estadual quanto municipal, com atuação, propostas político-pedagógicas e concepções formadoras distintas. A afirmação do presidente da República, Fernando Henrique Cardoso, feita em cadeia nacional de televisão ao anunciar a implantação do Plano de Valorização dos Professores, a partir de $1^{\circ}$ de janeiro de 1998, é um emblemático exemplo da permanência de concepções de décadas anteriores: "A questão é ter professor bem treinado e que tenha um salário digno." $\mathrm{O}$ discurso presidencial, neste caso, revela uma concepção pedagógica - no caso, a formação do professor do Ensino Fundamental, que não se assenta na vivência do professor, nos conflitos e desejos nascidos da sua experiência profissional. Daí, citar a necessidade de treinamento, uma concepção que, na acepção inglesa (training), tem o sentido de aprendizagem, ou instrução ao aprendiz. É um exemplo da permanência de traços do paradigma vigente em décadas anteriores e convivência com estudos e pesquisas que revelam uma revisão conceitual. Segundo Candau (1997), uma nova concepção elege a própria escola de Educação Básica como o locus da formação, que se contrapõe ao conceito de reciclagem

reciclar significa refazer o ciclo, voltar e atualizar a formação recebida [...] Trata-se, portanto, de uma perspectiva onde se enfatiza a presença nos espaços considerados tradicionalmente como o locus da produção do conhecimento [...]. Nesta perspectiva o locus privilegiado é a universidade.

(CANDAU,1997, p. 52-53)

A politização e a centralidade do espaço de sala de aula vêm sendo aprofundadas ao longo da primeira década do século XXI. Vale destacar a correspondência desse movimento com a emergência da valorização dos espaços privados e marcados pelas relações intersubjetivas no debate acadêmico que, muitas vezes, emergiu nos escritos pós-modernos de valorização das múltiplas manifestações culturais no cotidiano e na fragmentação das intenções dos sujeitos. O movimento de valorização do espaço de sala de aula, como espaço formativo e de 
construção de identidades profissionais, ganha contornos teóricos com as colaborações, em especial, de autores europeus.

Para Nóvoa (2000), um dos expoentes dessa nova vertente analítica, a projeção de novos significados do espaço escolar, advém da transição de uma concepção "técnica" de trabalho docente para perspectivas do professor reflexivo; de uma separação entre o lugar da prática e o lugar da teoria para a articulação entre o espaço escolar e o espaço universitário; e da descoberta do professor como pessoa para a necessidade de conceber espaços de autoconhecimento e de reflexão ética. Para esse autor, houve uma mudança do investimento da escola como projeto organizacional para um esforço de organizar ambientes favoráveis à formação e à inovação.

A consequência imediata desse tipo de abordagem foi a busca teórica do meso nível de análise, que pudesse articular o espaço escolar (dimensão micro) e o sistema educacional (dimensão macro). O dado comum das experiências reformistas, advindas desse novo posicionamento a respeito da experiência formativa dos profissionais da educação, foi a tomada de consciência de que é fundamental que a formação de professores aconteça dentro das escolas, como movimento reflexivo das tentativas, experimentações, demandas do processo formativo, adequação de projetos pedagógicos à realidade social, cujo protagonista é o professor.

A mudança de foco da valorização do saber experiencial levou ao reforço de análise coletiva das práticas da supervisão dialógica e do apoio profissional interpares, adotando como movimento formador a reflexão sobre a experiência. Nóvoa (1999) ressalta a importância da dimensão coletiva nas práticas de formação docente, especialmente as que, além de atender anseios pessoais e organizacionais, contribuam para reforçar as vivências coletivas da profissão. Segundo esse autor,

esta preocupação desponta em vários textos: na proposta de supervisão dialógica de Duncan Waite; na referência ao jogo colectivo feita por Rui Canário; no conceito de critical friend mobilizado por Idália Sá-Chaves, Elsa Pires, Anabela Carvalho e Paula Ferreira; na metáfora da libertação trazida por Maria Alfredo Moreira, Flávia Moreira e Isabel Marques; no princípio da supervisão clínica de tipo colaborativo formulado por Lúcia Oliveira; etc. (NÓVOA, 1999, p.5) 
A mudança de paradigma em relação ao processo formativo gerou, em alguns casos, a consolidação de "comunidades profissionais" e de "movimentos pedagógicos", concebidos como lugares de formação. Em Portugal, por exemplo, durante o processo de reforma educacional, no início da década de 1990 do século passado, uma rede nacional com cerca de duzentos Centros de Formação, foi criada a partir da iniciativa de professores e escolas. Contudo, tal movimento nunca foi um ponto pacífico na experiência brasileira.

A tradução dessas observações, nos encontros dedicados ao debate dos projetos educacionais, foi a consagração do espaço escolar como locus privilegiado da articulação entre a formação inicial (Universidade) e a formação continuada, que, nos programas de formação desenvolvidos por várias reformas educacionais em curso, foram denominadas como "formação em serviço", valorizando o cotidiano e as práticas educativas realizadas em sala de aula como formuladores da pauta dos programas de formação profissional.

Se o reconhecimento do professor como investigador e protagonista das práticas educativas gera certo consenso teórico, as condições para sua realização não chegaram a se efetivar. Mesmo após trinta anos em que tal questão está presente em estudos e pesquisas educacionais, ainda é incipiente a instalação de condições concretas que reforcem as práticas de pesquisa e de produção escrita dos professores no interior do sistema educacional. Em suma, ainda há pouca produção do próprio professor, assim como é restrito o reconhecimento científico e editorial de sua produção. A prática docente acaba sendo apenas objeto de estudo e uma forma de universitários legitimarem seus livros, suas pesquisas.

$O$ debate em que se insere o novo estatuto da formação docente sugere, entretanto, um espaço mais complexo de constituição do profissional em questão. Se o espaço da prática concreta do docente passa a ser considerado como espaço formativo por excelência, é necessária a absorção da complexa relação entre comunidade, aluno e professor como eixo do processo formativo.

\section{O PROJETO RESIDÊNCIA DOCENTE NO CP}

Que fosse assim dum jeito misturado com o-de-todo-dia da vida da gente daqui. Que podia ser um modo desses de juntar 
O Residência Docente, assim como outros projetos desenvolvidos na escola, consolidam o papel do CP/UFMG ${ }^{1}$ como lugar de formação docente. Trata-se da implementação de uma política de formação que alia as reflexões acadêmicas e os desafios cotidianos de uma escola de Ensino Fundamental de forma ampliada para a rede pública de Educação Básica mineira. Além da experiência na formação docente, que o CP/UFMG consolidou ao longo do desenvolvimento de suas atividades, a proposição do projeto Residência Docente teve como referência o Programa do Colégio Pedro II (Rio de Janeiro). Os residentes docentes são professores da rede pública municipal de Contagem, com diploma de Licenciatura Plena ou de formação específica para os Anos Iniciais do Ensino Fundamental. Concomitante com a docência em tal rede de ensino, desenvolvem as seguintes atividades no CP/UFMG: observação em sala de aula; participação em reuniões de instâncias gestoras, de supervisão e de orientação; e exercício da docência como ministrante da disciplina GTD - Grupo de Trabalho Diferenciado. Vale destacar que o GTD é um projeto coletivo dos três ciclos da escola e tem como objetivo respeitar o ritmo, o tempo e as experiências de cada educando. De acordo com diagnóstico feito pelos professores, os alunos são agrupados segundo demandas detectadas independente do ano escolar, mas no próprio ciclo.

Os momentos de formação visam suscitar oportunidades de reflexões de cunho individual e compartilhadas, buscando construir espaços e momentos coletivos na organização dos tempos e espaços escolares. A intenção é instaurar rotinas de debates e de formação entrepares, bem como novas temáticas que possam gerar pesquisas e investigações no campo da Educação Básica, do ensino e da aprendizagem.

\footnotetext{
${ }^{1} O$ Centro Pedagógico tem sua origem no antigo Ginásio de Aplicação da UFMG, criado em cumprimento aos dispositivos legais instituídos, em 1946, pelo Decreto Lei $n^{\circ} 9053$. Esse Decreto obrigou as Faculdades de Filosofia Federais a manterem uma escola destinada à prática docente dos alunos matriculados em seus cursos de Didática. São objetivos do Centro Pedagógico: ministrar o Ensino Fundamental, tendo-o como base investigativa para a produção de conhecimento, de ensino e de pesquisa; constituir-se como campo de reflexão e de investigação sobre a prática pedagógica; constituir-se como espaço de novas experimentações pedagógicas, que subsidiem avanços e reflexões sobre a prática educativa; ser um campo de experimentação para a formação de professores.
} 
Vários fatores foram considerados para a escolha da rede municipal de Contagem para a participação no Residência Docente: a proximidade geográfica, que permite ao residente a presença no CP/UFMG concomitante ao exercício da docência; os índices sobre a competência de leitura e interpretação de textos ou para a resolução de problemas de alunos de $5^{\circ}$ e $9^{\circ}$ anos do Ensino Fundamental; e, de forma determinante, a possibilidade de ultrapassar uma mera situação de aprendizagem individual e atuar com um coletivo docente de uma escola. Sobre os dois últimos teceremos algumas considerações a seguir.

\subsection{COMPETÊNCIA PARA LEITURA, INTERPRETAÇÃO DE TEXTOS E RESOLUÇÃO DE PROBLEMAS}

São quatorze as escolas participantes do projeto Residência Docente CP/CAPES/Contagem em 2014. A maioria delas localiza-se na região denominada "Vargem das Flores". Segundo dados da Prova Brasil (2011) e dados do INEP, a proporção de alunos das escolas municipais de Contagem que aprenderam o adequado em competência de leitura e interpretação de textos ou na resolução de problemas (até o $5^{\circ}$ ano e até o $9^{\circ}$ ano) é bastante limitada, até mesmo inferior em relação às escolas estaduais dessa cidade.

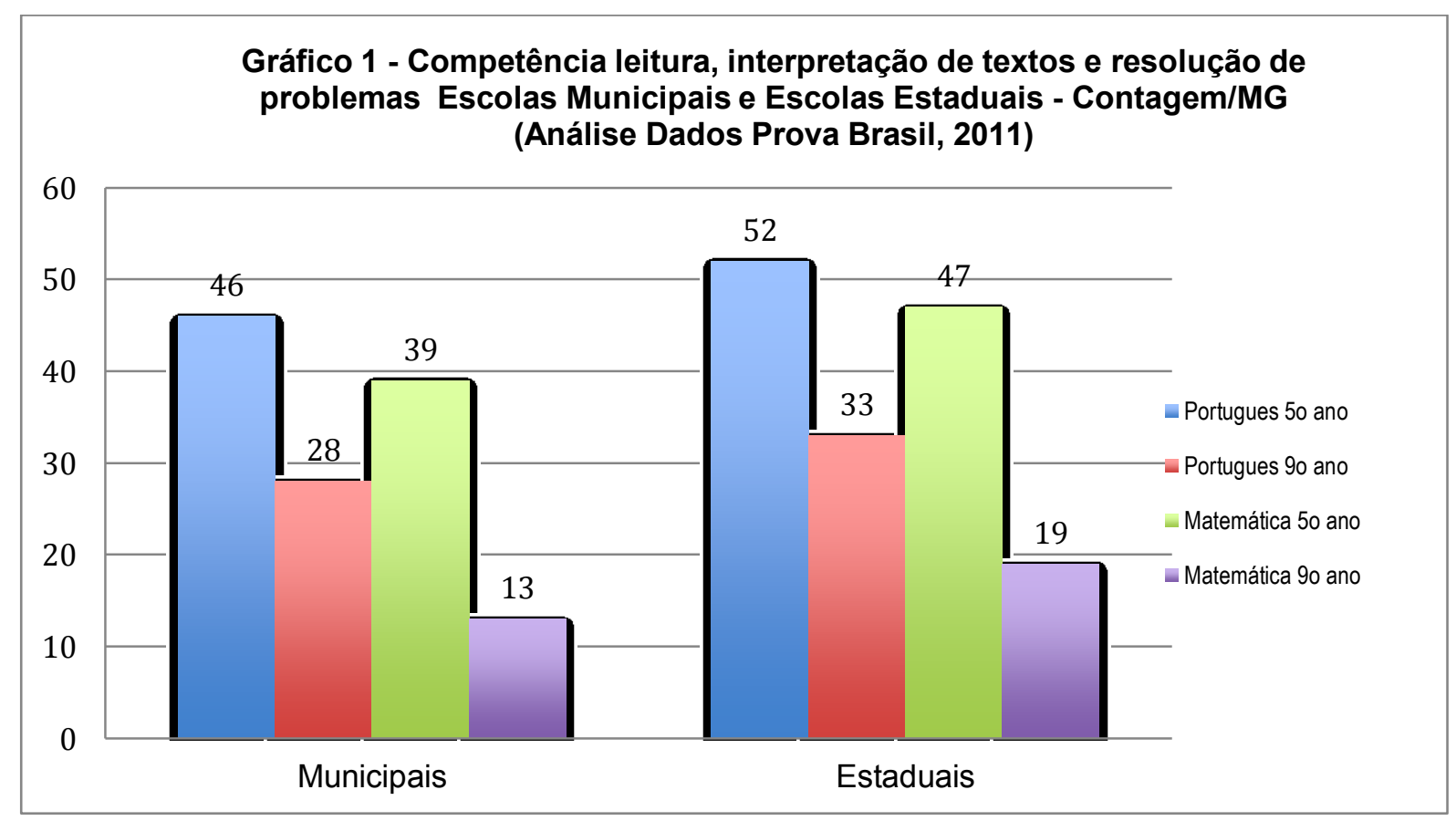


Fonte: Elaborado pela autora, a partir de dados da Prova Brasil - INEP (2011).

Tanto nos anos iniciais como nos anos finais do Ensino Fundamental, a maioria das escolas municipais de Contagem está em situação de "Atenção" ou de "Alerta", como revela o gráfico a seguir.

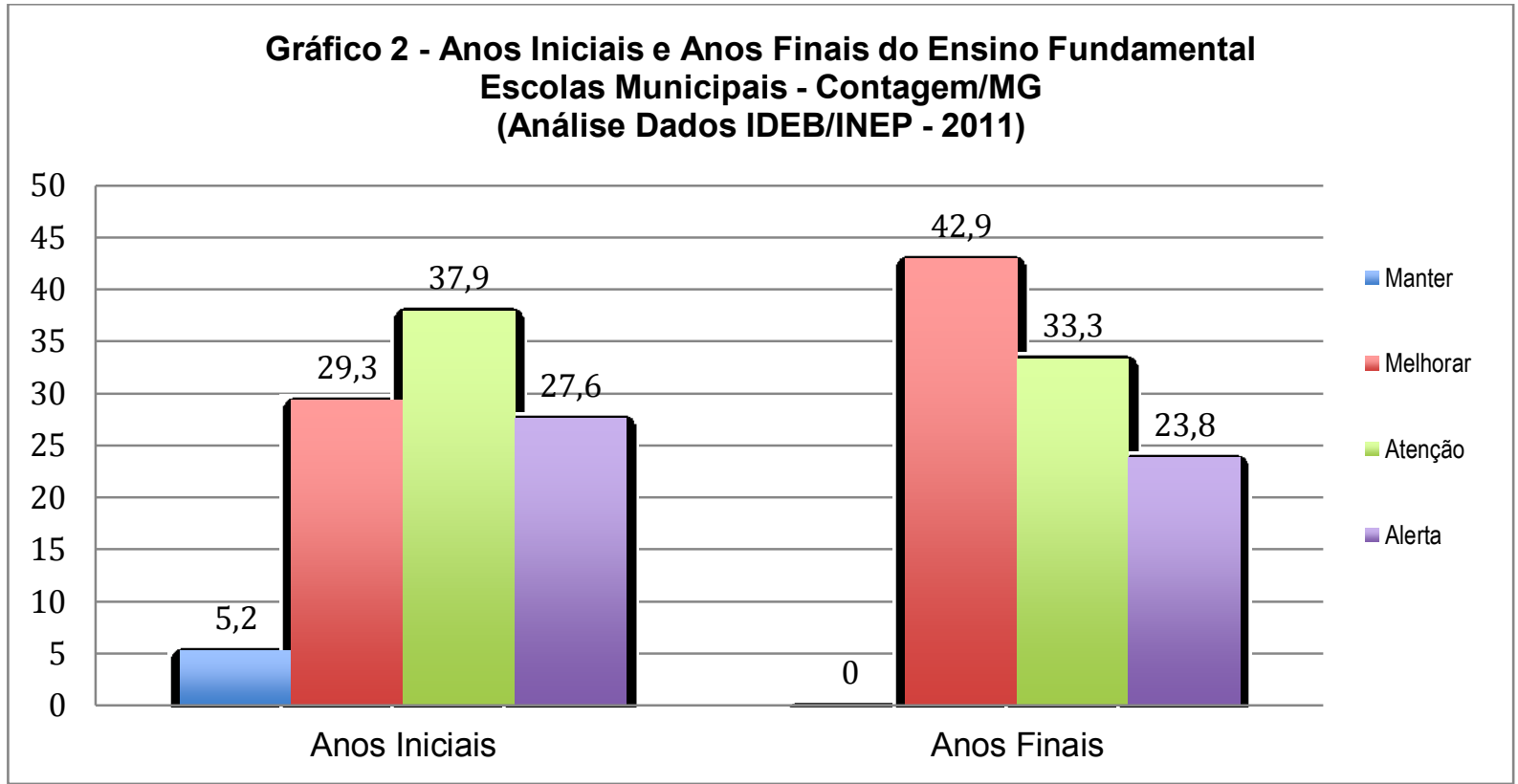

Fonte: Elaborado pela autora a partir de dados IDEB/INEP (2011).

No caso específico das escolas municipais participantes do projeto Residência Docente há uma situação bastante delicada referente ao aprendizado dos alunos, ainda segundo os dados da Prova Brasil 2011. No tocante aos anos finais do Ensino Fundamental das escolas da região Vargem das Flores - tanto em relação às competências em leitura e interpretação de textos ou na resolução de problemas - a situação se agrava. Na área de Matemática, com exceção de apenas uma escola, os índices estão abaixo ou próximos de 10\%. Em outras palavras, somente esse percentual reduzido de alunos demonstrou competência na resolução de problemas ao término do Ensino Fundamental. Mesmo a escola que apresentou os índices mais altos teve apenas $25 \%$ dos alunos de $9^{\circ}$ ano com aprendizado adequado em Matemática. 
Quadro 2- Proporção de alunos com aprendizado adequado à sua etapa escolar

\begin{tabular}{|l|c|c|c|c|}
\hline \multicolumn{1}{|c|}{ ESCOLA } & $\begin{array}{c}\text { Português } \\
\mathbf{5}^{\mathbf{0}} \text { ano } \\
\mathbf{( \% )}\end{array}$ & $\begin{array}{c}\text { Português } \\
\mathbf{9}^{\mathbf{0}} \text { ano } \\
\mathbf{( \% )}\end{array}$ & $\begin{array}{c}\text { Matemática } \\
\mathbf{5}^{\circ} \text { ano } \\
\mathbf{( \% )}\end{array}$ & $\begin{array}{c}\text { Matemática } \\
\mathbf{9}^{\circ} \text { ano } \\
\mathbf{( \% )}\end{array}$ \\
\hline Anexo Estudante Nathalia Teixeira & - & - & - & - \\
\hline EM Ápio Cardoso & 27 & 15 & 15 & 5 \\
\hline EM Francisco Sales da Silva Diniz & 36 & 19 & 29 & 6 \\
\hline EM Giovanini Chiodi & 30 & 10 & 20 & 2 \\
\hline EM Hilda Nunes dos Santos & 19 & 16 & 11 & 3 \\
\hline EM Ivan Diniz Macedo & 33 & 14 & 27 & 4 \\
\hline EM Josefina de Souza Lima & 22 & 31 & 28 & 13 \\
\hline EM Maria do Carmo Orechio & 35 & - & 49 & - \\
\hline EM Maria Silva Lucas & 34 & 14 & 29 & 6 \\
\hline EM Nossa Senhora Aparecida & 49 & 50 & 50 & 25 \\
\hline EM Paulo Cézar Cunha & 29 & 14 & 16 & 5 \\
\hline EM Prof. Wancleber Pacheco & 38 & 24 & 31 & 10 \\
\hline EM Profa. Ana Guedes Vieira & 40 & 21 & 27 & 5 \\
\hline EM Vereador José Ferreira de Aguiar & 46 & 21 & 31 & 18 \\
\hline
\end{tabular}

Legenda $\quad 0 \%$ $100 \%$

OBS: $70 \%$ é a proporção de alunos que deve aprender o adequado até 2022, segundo o Movimento Todos pela Educação.

Fonte: Elaborado pela autora a partir de dados da Prova Brasil - INEP (2011).

\subsection{DESENVOLVIMENTO PROFISSIONAL, PRÁTICA DOCENTE E TRABALHO COLETIVO}

A experiência acumulada no desenvolvimento de projetos e ações de formação docente no CP/UFMG nos leva a acreditar em um processo de formação que acarrete tanto o desenvolvimento profissional individual, como, e especialmente, alterações na prática docente e, consequentemente, no espectro maior, na instituição escolar. Segundo Nóvoa (1999, p.18),

é impossível imaginar alguma mudança que não passe pela formação de professores. Não estou a falar de mais um "programa de formação" a juntar a tantos outros que todos os dias são lançados. Quero dizer, sim, da necessidade de uma outra concepção, que situe o desenvolvimento pessoal e profissional dos professores, ao longo dos diferentes ciclos da sua vida. Necessitamos de construir lógicas de formação que valorizem a experiência como aluno, como aluno-mestre, como estagiário, como professor principiante, como professor titular e, até, como professor reformado. 
Tal perspectiva - construir condições de reflexão/ação/reflexão de forma a atingir a instituição escolar e não apenas os sujeitos individualmente - foi determinante na definição dos participantes do Residência Docente - CAPES/CPUFMG.

Várias são as iniciativas de formação no formato de palestras e eventos em que os professores são convidados a participar nos últimos anos. No entanto, tais iniciativas propiciam pouco impacto no que tange uma intervenção qualificada nos tempos e espaços escolares. O próprio conceito de desenvolvimento profissional docente vem passando por diferentes ressignificações, acompanhando as alterações do processo educacional. Nesse sentido, o desenvolvimento profissional docente teria as seguintes características: processo mais longo, que propicie a relação entre as novas experiências e os conhecimentos tácitos dos docentes advindos de sua prática pedagógica; papel protagonista do professor no processo de relacionar e questionar a própria prática; processo colaborativo na perspectiva de reconstrução da cultura escolar.

Segundo Sparks e Hirsh (1997 apud MARCELO, 1999), as mudanças relativas ao desenvolvimento profissional docente são:

- de um desenvolvimento profissional orientado para o desenvolvimento do indivíduo para outro orientado para o desenvolvimento da organização;

- de um desenvolvimento profissional fragmentado e desconexo para um coerente e orientado por metas claras;

- de uma organização da formação a partir da administração para outra centrada na escola;

- de uma focagem centrada nas necessidades dos adultos para outra centrada nas necessidades de aprendizagem dos alunos;

- de uma formação desenvolvida fora da escola para formas múltiplas de desenvolvimento profissional realizadas na escola;

- de uma orientação baseada na transmissão aos docentes de conhecimentos e das competências feita por especialistas ao estudo dos processos de ensino e de aprendizagem pelos professores; 
- de um desenvolvimento profissional dirigido aos professores, como principais destinatários, a um outro dirigido a todas as pessoas implicadas no processo de aprendizagem dos alunos;

- de um desenvolvimento profissional dirigido ao professor, a título individual, à criação de comunidades de aprendizagem, em que todos - professores, alunos, diretores, funcionários - se consideram, simultaneamente, professores e alunos.

Como já afirmado, a opção por desenvolver o projeto Residência Docente CAPES-CP/UFMG, em 2014, junto à rede municipal de Contagem teve como embasamento pedagógico e político as premissas acima destacadas. Para isso, foram necessárias várias reuniões junto à equipe gestora da Secretaria, que definiu como foco de desenvolvimento do projeto escolas da região Vargem das Flores. A equipe docente ${ }^{2}$ realizou reunião com diretores das escolas da referida região, apresentando o projeto detalhadamente. A divulgação junto aos professores dessas escolas foi feita pelas respectivas direções, tendo como suporte um folder e uma apresentação em Power Point. O processo de definição de quem seria o residente foi desenvolvido sob os auspícios da direção da escola e da Secretaria Municipal de Educação de Contagem.

\title{
3.3 SOBRE O PROCESSO DE FORMAÇÃO
}

\begin{abstract}
A formação terá como base uma reflexão dos sujeitos sobre sua prática docente, de modo a permitir que examinem suas teorias implícitas, seus esquemas de funcionamento, suas atitudes etc., realizando um processo constante de auto avaliação que oriente seu trabalho. A orientação para esse processo de reflexão exige uma proposta crítica da intervenção educativa, uma análise da prática do ponto de vista dos pressupostos ideológicos e comportamentais subjacentes. (IMBERNÓN, 2001, p. 48-49).
\end{abstract}

É importante destacar que o processo de formação docente se dá em diversas instâncias: nas reuniões da equipe docente ou entre supervisores e residentes, nos encontros de formação geral ou via ambiente virtual.

As reuniões da equipe docente seja para delinear a acolhida aos residentes antes da "aula inaugural"; definir os procedimentos comuns; planejar as atividades

\footnotetext{
2 Nesse texto denominaremos de "equipe docente" o grupo formado pela coordenação geral, coordenação acadêmica; coordenação de área e supervisores.
} 
coletivas ou compartilhar os encaminhamentos específicos de cada área, constituem-se como momentos significativos de construção coletiva.

O acompanhamento dos residentes, realizado pelos supervisores, tem como eixo norteador questões suscitadas pela observação de aulas e atividades no CP/UFMG ou pelo exercício docente na escola de origem. São também importantes momentos de formação docente, conforme revelam os trechos de registros de supervisores e ou de coordenadores de área, a seguir:

\begin{abstract}
"Durante o primeiro semestre, foram desenvolvidas atividades ligadas ao conhecimento sobre a rotina do $\mathrm{CP}$, assim como sua estrutura de funcionamento. As atividades estavam relacionadas à observação dos espaços e à conversa com os funcionários dos mais diversos setores. $O$ objetivo era que os residentes se sentissem mais à vontade, integrados ao ambiente e ao seu funcionamento. Paralelamente, foram designadas tarefas que levariam ao embasamento teórico com leituras, fichamentos e discussão sobre o que foi lido. [...] O acompanhamento das aulas e do professor foi importante para que houvesse uma identidade com a turma e o processo de criação do projeto de intervenção acontecesse de maneira bem natural entre o professor da área, a turma e o residente. É importante destacar que o residente $A^{3}$ está ministrando um GTD denominado "Maleta Literária" desde o início de agosto, para o segundo ciclo, às quartas-feiras [...]. Ele está sob a minha orientação e, também, o incentivei a fazer disciplina isolada para o Mestrado na Faculdade de Letras da UFMG. Ele aceitou o desafio e está matriculado em duas disciplinas" (Supervisora Português).
\end{abstract}

"Até o presente momento estabelecemos uma proposta de trabalho considerando-se a importância de discutirmos temas referentes à Matemática e à Língua Portuguesa. Nossos encontros de formação da Pedagogia acontecem logo após a reunião de formação geral e são orientados pela leitura de textos indicados previamente de acordo com a bibliografia da área. Os textos para a leitura são acompanhados por uma orientação de estudos. Essa orientação consiste em perguntas que devem ser analisadas pelos Residentes. Teoria e prática são discutidas de modo a refletir sobre o trabalho desenvolvido nas escolas. Para abordagem do estudo sobre alfabetização e letramento os participantes levaram para a reunião dados referentes à escrita e à produção de textos dos seus alunos. As discussões foram importantes no sentido de problematizar as ações práticas e o modo de compreender a alfabetização na perspectiva do letramento. Intervenções para o trabalho foram discutidas. As reuniões de orientação/supervisão ocorrem individualmente ou em duplas, semanalmente com todos os participantes. Nesses momentos são discutidos temas relativos ao processo ensino e aprendizagem dos alunos, a prática da sala de aula, disciplina, pesquisa, o Projeto de Intervenção, Memorial e artigo. Os Residentes têm participado de diversas ações do $1^{\circ}$ Ciclo, sejam elas junto aos alunos ou relativas ao trabalho dos professores. Destacam-se participação em eventos culturais, palestras, seminários, colóquio internacional, Defesa de Tese e Grupos de Pesquisas, eventos

\footnotetext{
${ }^{3}$ Os nomes de residentes, supervisores, professores estão, nesse texto, substituídos por letras,
} visando preservar a identidade de cada um, conforme solicitado por alguns. 
esses vinculados à Faculdade de Educação. Para os próximos encontros de Formação estão previstas discussões sobre Alfabetização, História e Geografia e Ciências" (Coordenadora Pedagogia).

"Sobre o trabalho dos residentes: o residente $B$ está acompanhando de forma muito adequada o aluno M.A. (síndrome de Asperger). Inscrevemos juntos o trabalho "Ambientes digitais para todos" na FEBRAT 2014 e ele foi aprovado. [...] em sua escola em Contagem vai desenvolver um projeto utilizando-se a metodologia do projeto Nossa Escola Pesquisa Sua Opinião (NEPSO), com o tema de interesse dos alunos da turma - EJA: Maconha provavelmente em torno do assunto descriminalização; o residente $C$ teve que alterar a turma que estava acompanhando devido ao fato de nosso horário de aula ter sido alterado no segundo semestre. Está acompanhando uma turma do oitavo ano (8A). Sua atividade será a elaboração e aplicação de uma sequência didática com o tema Sistema Nervoso. [...] ela já desenvolve uma atividade denominada Clube; o residente $C$ está participando das atividades do Clube de Ciências, acompanhando alunos do nono ano (K e FC). Os trabalhos estão sendo inscritos na FEBRAT 2014. [...] em sua escola em Contagem deverá realizar uma ação semelhante ao que está desenvolvendo com seus alunos de incentivo a leitura de textos/artigos relativos às Ciências "Coceiras de Ciências"(Supervisora Ciências).

"Hoje as Residentes de Arte apresentaram o que desenvolveram até o presente momento em seus Memoriais para todos do grupo. Depois todos nós discutimos cada projeto de intervenção. Foi um encontro rico de muitas trocas e contribuições. Foi muito emocionante também! Todas disseram da importância deste curso na vida delas [...] Excelente!" (Coordenador Arte).

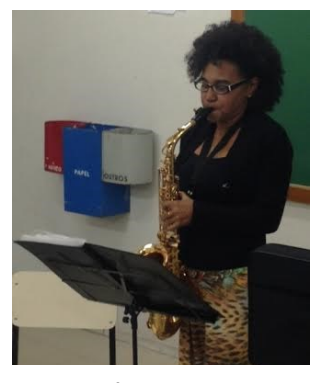

Foto: Residente de Arte faz sua apresentação

"Devido ao horário de cada residente de História, as reuniões de supervisão têm sido individuais. As questões discutidas têm variado conforme as demandas deles e, na realidade, poucas giram em torno de questões específicas do conhecimento histórico. Preocupações e desafios da docência têm prevalecido. [...] questões básicas da temporalidade histórica serão objeto de reflexão e estudos nas próximas reuniões" (Supervisora História).

"Todos os residentes da matemática se encontram na escola na quintafeira. Este foi um ponto muito positivo, para a realização das atividades e desenvolvimento de uma proposta de trabalho que busca associar teoria à prática. Durante o primeiro semestre optamos por uma discussão teórica sobre diversos assuntos relacionados à Educação, em especial a Educação Matemática. Os alunos acompanharam diversos anos escolares, não apenas o professor orientador, mas todos os demais anos $\left(5^{\circ}, 6^{\circ}, 7^{\circ}, 8^{\circ}\right.$, e $\left.9^{\circ}\right)$. Não acompanharam o $4^{\circ}$ ano, pois na quinta-feira não tem aula de Matemática. Para o acompanhamento em todos os anos escolares, contamos com a colaboração de todos os professores do Núcleo de Matemática. Os residentes estão desenvolvendo em sua escola em Contagem um projeto de pesquisa de opinião com os alunos, utilizando da metodologia NEPSO (Nossa escola pesquisa sua opinião). A ideia é que os alunos participem da apresentação de trabalhos na FaE no mês de novembro. [...] Durante o segundo semestre os residentes estão 
desenvolvendo atividades práticas com o uso do software GeoGebra para aplicar nas escolas em que atuam como docentes. Inclusive um dos professores encaminhou para o TI do CP um laptop, muito similar ao UCA para entender como instalar o software. Após as devidas explicações, o mesmo instalou em todos os laptops de sua escola, pois pretende utilizar em sala de aula"(Coordenador Matemática).

Além dos momentos de supervisão, que ocorrem semanalmente e têm dinâmicas diversas e específicas de cada área, como revelam os depoimentos citados, os residentes participam de uma reunião mensal ${ }^{4}$, denominada de "Formação Geral". Nessas são abordadas questões gerais do campo educacional ou do projeto Residência Docente, tais como: Memorial de Percurso; Projetos de Trabalho; Pesquisa como Ensino; Letramentos: Alfabetização e Letramento, Leitura, Produção de texto e Letramento Literário na Educação Básica; Sequencia Didática; Espaços não formais de aprendizagem; O lugar da Educação Física no currículo escolar. Trata-se de um momento em que as reflexões perpassam ou mesmo ultrapassam as questões específicas das disciplinas escolares revelando desafios da prática pedagógica de residentes, supervisores e coordenadores de diferentes áreas do conhecimento ${ }^{5}$.

\subsection{AMBIENTE VIRTUAL}

A Plataforma Moodle ${ }^{6}$ é mais um espaço de formação que possibilita interação entre os participantes da equipe docente e os residentes, para diálogos sobre os conteúdos curriculares e esclarecimentos de dúvidas. São duas salas/ambientes distintos: um exclusivo para a equipe docente e outro dela com todos os residentes. No início do ano, os residentes foram convidados para uma oficina sobre a Plataforma Moodle e receberam um tutorial com as especificidades

\footnotetext{
${ }^{4} \mathrm{O}$ cronograma das reuniões de Formação Geral foi entregue a cada residente e disponibilizado no ambiente virtual.

${ }^{5}$ A pertinência das temáticas para educadores em geral despertou o interesse de diversos diretores e coordenadores pedagógicos das escolas participantes do Projeto Residência Docente, em reunião realizada na Secretaria de Educação de Contagem. Diante disso, além do convite para participação das reuniões de formação geral, foi criada uma sala no ambiente virtual (Plataforma Moodle) para que coordenação do projeto, direção e coordenação pedagógica das escolas pudessem compartilhar avaliações e questões sobre o projeto.

${ }^{6}$ Trata-se de uma ferramenta tecnológica de gestão de cursos a distância ou como apoio ao ensino físico-presencial, utilizada no mundo inteiro por instituições de ensino acadêmico e profissional, dentre elas, a UFMG. A sigla MOODLE significa Modular Object-OrientedDynamic Learning Environment.
} 
do ambiente Residência Docente. A sala virtual que os residentes têm acesso é composta de uma parte geral e uma parte específica de sua área de formação (Arte, Ciências, Educação Física, Geografia, História, Língua Inglesa, Língua Portuguesa, Matemática e Pedagogia). A parte geral é composta com os seguintes itens:

- Fóruns Gerais (Fórum de notícias, Fórum de Dúvidas e Fórum de Apresentação);

- Sobre o projeto Residência Docente (Fórum Trocando ideias e Material de Apoio);

- Sobre a Plataforma Moodle (Fórum Conversando sobre a Plataforma e Material de Apoio sobre Moodle);

- Sobre Memorial (Fórum Conversando sobre Memorial eMaterial de Apoio sobre Memorial);

- Sobre Trabalho de Conclusão do Curso TCC (Fórum Conversando sobre o TCC, Arquivo Apresentação TCC, Arquivo Elaborando um Projeto);

- Sobre Planejamento (FórumConversando sobre Planejamento e Material de Apoio Sequencia Didática).

Cada módulo referente à parte específica é composto por discussões e reflexões pertinentes às questões do grupo e sob a gestão da coordenação de área e supervisores. O formato delineado busca manter tanto as linhas gerais e comuns, como a diversidade advinda da especificidade de cada área do conhecimento e dos sujeitos envolvidos nos respectivos grupos.

\subsection{REGISTRO DO VIVIDO - FONTE DA REFLEXÃO}

Para fomentar o processo ação / reflexão / ação e para que a prática se transforme em experiência, o registro assume um papel fundamental. Segundo Weffort (1996 apud RICCI, 2007),

este aprendizado do registro é o mais poderoso instrumento na construção da consciência pedagógica e política do educador. Pois, quando registramos, tentamos guardar, prender fragmentos do tempo vivido que nos é significativo, para mantê-lo vivo. Não somente como lembranças, mas como registro de parte de nossa história, nossa memória. Através destes registros construímos nossa memória pessoal e coletiva. [...] a ação de registrar, em linguagem verbal ou não verbal, nos possibilita rever nossa ação e melhor apreendê-la. [...] a reflexão trabalha o pensamento e, o seu 
registro, permite que se supere o mundo das lembranças. A reflexão registrada tece a memória, a história do sujeito e de seu grupo. Sem a sistematização deste registro refletido não há apropriação do pensamento do sujeito-autor.

Nessa perspectiva, para que os residentes exercessem a autoria da memória individual e refletissem sobre sua prática docente, vários instrumentos para facilitar 0 registro foram criados: "Impressões"; "Relatório Reflexivo Semestral"; "Proposta de GTD”; “Avaliação de GTD” e "Caderno de Campo”.

Instrumentos para o registro também se fizeram presentes para a equipe docente: desde um quadro de horários para o acompanhamento da presença e a avaliação dos residentes, como o desenvolvimento da pesquisa Residência Docente: formação e experiência profissional. Visando delinear o perfil dos residentes e levantar dados para a avaliação e aprimoramento do projeto, foi disponibilizado no ambiente virtual um questionário composto por questões objetivas e abertas divididas em três partes: "Perfil socioeconômico"; "O CP e o Projeto Residência" e "Ser Docente". A análise preliminar dos dados revela que a maioria dos residentes é do sexo feminino (74\%); tem idade entre 46 a 50 anos; não assina ou compra revistas ou jornais periodicamente e vai ao cinema esporádica ou raramente. Em relação à frequência de leitura, há um empate entre os que leem esporádica e frequentemente, sendo que a preferência da maioria recai sobre os romances. A avaliação que fazem do CP/UFMG é bastante positiva, assim como sobre a equipe docente. As críticas à escola se restringem aos aspectos de infraestrutura tais como a falta de quadra coberta e sinalização dos espaços. Quase a totalidade (94\%) se diz satisfeita com a proposta de formação propiciada pelo Residência Docente. A intenção em enfatizar o diálogo entre saberes e fazeres, evitando a perspectiva de hierarquização na relação Universidade e Educação Básica, parece ter se concretizado, como revelamos residentes ao indicarem os aspectos relevantes do Residência Docente:

"Troca de experiências; contraponto - porque nossos pontos de partida (formação, locais onde trabalhamos e relações profissionais) são radicalmente diferentes e é diante dessas diferenças que tento imaginar possibilidades; reencontrar meus professores da graduação em uma relação horizontalizada - não que antes houvesse um distanciamento acentuado entre nós, é que era uma relação de aluno e professor e agora somos todos professores!" 
"Troca de experiências, os textos teóricos para leitura, os encontros com orientação onde posso aprender mais e falar sobre a minha experiência."

"A troca de experiências com outros profissionais; a forma de trabalhar da Professora S. que está ampliando meu horizonte; os desafios apresentados no decorrer do curso."

"A iniciativa do projeto; a oportunidade de melhorar minha prática docente; momento de troca de experiências."

"Tempo para debater sobre assuntos pertinentes a educação; observar metodologias diferentes."

A presença da expressão "troca de experiências" na maioria das respostas a uma questão aberta é bastante significativa, da mesma forma que a reincidência de "compromisso", "criatividade", "gostar do que faz" na indicação de características de ser docente.

\title{
4 ALGUMAS CONSIDERAÇÕES
}

\begin{abstract}
A educação é permanente não por que certa linha ideológica ou certa posição política ou certo interesse econômico o exijam. A educação é permanente na razão, de um lado, da finitude do ser humano, de outro, da consciência que ele tem de finitude. Mas ainda, pelo fato de, ao longo da história, ter incorporado à sua natureza não apenas saber que vivia, mas saber que sabia e, assim, saber que podia saber mais. A educação e a formação permanente se fundam aí. (FREIRE, 1997, p. 20).
\end{abstract}

O desenvolvimento do projeto Residência Docente tem proporcionado, a todos os envolvidos, uma experiência ímpar de formação. Os relatos confirmam que o principal objetivo, qual seja, o de "contribuir para a formação de professores da rede pública de Educação Básica, a partir de vivências e reflexões sobre o fazer pedagógico, no Ensino Fundamental, nas suas dimensões teóricas e práticas" tem se concretizado.

Essa contribuição se traduz na socialização da proposta político pedagógica e a experiência do CP com os residentes, que têm feito de suas observações e intervenções objeto de reflexão para o desenvolvimento de estratégias didáticas e pedagógicas ou de projetos nas escolas em que atuam como docentes.

Como afirmado anteriormente, os residentes estão, sob orientação e supervisão, lendo; discutindo em formato de seminário; oferecendo GTD; participando de reuniões docentes, de eventos culturais, palestras, seminários, 
colóquio internacional, defesa de tese e grupos de pesquisas e, até mesmo, como ouvinte em curso de Mestrado da Faculdade de Educação/UFMG. Vários inscreveram e tiveram seus trabalhos aprovados tanto na Feira de Colégios de Aplicação (FEBRAT) como outros congressos acadêmicos. Essas iniciativas são objeto de reflexão coletiva, assim como tema nos relatórios de atividades.

Muitos residentes estão provocando mudanças nas escolas em que atuam como docentes ao implementar projetos similares aos desenvolvidos no Centro Pedagógico, como os que utilizam a metodologia do Nossa Escola Pesquisa Sua Opinião (NEPSO) ou o Clube de Ciências. No entanto, há alguns residentes que se restringem a estabelecer comparações entre as condições do CP/UFMG e das escolas onde atuam como docentes, que, segundo eles, são limitadoras.

A experiência tem também provocado mudanças institucionais, como por exemplo, um projeto de Lei da SEDUC Contagem que cria o cargo de 40 horas para os professores que atuam na região da maioria das escolas dos residentes, visando oferecer melhores condições para a permanência desses profissionais. Há também, por parte dessa Secretaria, a expectativa de uma "segunda edição do Residência Docente" envolvendo mais professores da região de Nova Contagem e ampliando a oferta de vagas para residentes no Colégio Técnico, pois há no município a Fundação de Ensino de Contagem (FUNEC), que foi inaugurada há 41 anos e atende, em média, 2500 estudantes anualmente entre os cursos integrados, concomitantes e de qualificação via Pronatec.

Buscando tecer uma comunidade de aprendizagem coletiva, fugindo da mera qualificação individual, os diretores das escolas onde os residentes atuam como docentes foram convidados a participar de forma mais intensa do projeto.

No tocante às perspectivas futuras do projeto Residência Docente, a equipe gestora tem dado encaminhamento para institucionalizá-lo como um curso de especialização junto às instâncias internas ao Centro Pedagógico e da Universidade Federal de Minas Gerais. Dentre as providências, por exemplo, está a elaboração da definição da Matriz Curricular.

Além disso, está envidando esforços no sentido de constituir, com alguns residentes, um Grupo de Estudos e Pesquisas, para que tais profissionais se tornem referência na comunidade escolar para o processo de aprendizagem da profissão docente e autonomia na formação. 
Finalmente, vale destacar a observação de alguns residentes sobre as condições adversas das escolas onde atuam como docentes para a implementação de ações desenvolvidas no CP/UFMG. Este não é um tema menor para as políticas públicas nacionais, em especial pelo conflito aberto pelas reformas educacionais dos anos 1990 e do início do século XXI. As metodologias adotadas na implantação dessas reformas, não raro, geraram tensões entre as exigências de inovação pedagógica e de formação docente e as condições de trabalho, tanto administrativas- módulo aula fixo; ausência de tempo coletivo; fragmentação e descontinuidade de atividades de formação; entre outros - quanto de infraestrutura dos equipamentos escolares. O projeto Residência Docente, de certa maneira, supera esse equívoco metodológico ao evitar a formulação exógena à prática docente do residente e os percalços cotidianos por ele enfrentados. Contudo, permanece uma tensão instigante, qual seja, o projeto em si não soluciona as insuficiências dos equipamentos escolares, visto que o Residência Docente se constitui em um meso espaço de formulação e experimentação. Em outras palavras, não se trata do macro espaço tão acionado nas reformas educacionais de 1990 (Ministério de Educação, Secretarias Estaduais de Educação e Congressos Sindicais e Acadêmicos da área educacional), nem do micro espaço das iniciativas pessoais de docentes em suas salas de aula. Trata-se de um espaço de confronto e reformulação, ou até mesmo de intersecção entre os fazeres e saberes docentes. Configura-se, assim, um espaço de tensão criativa, tal como expressou o residente ao afirmar que o diálogo entre a sua experiência e do supervisor tinham pontos de partida "radicalmente diferentes", mas, diante deles, abriam-se possibilidades que emergiam na horizontalidade da relação entre docentes da Educação Básica que têm como foco de exercício e pesquisa a própria Educação Básica.

\section{CLÁUDIA SAPAG RICCI}

Doutora em História Social. Pós-doutoramento em Ciências da Educação - História e Ciências Sociais (CIED/UMinho - Braga/Portugal). Professora associada da Universidade Federal de Minas Gerais - Centro Pedagógico.

\section{REFERÊNCIAS}


BRANDÃO, C. R.A questão política da educação popular. São Paulo: Brasiliense, 1982.

BRASIL. Lei no 11.502 de 11 de julho de 2007. Modifica as competências e a estrutura organizacional da fundação Coordenação de Aperfeiçoamento de Pessoal de Nível Superior - CAPES. Disponível

em:<http://www.planalto.gov.br/ccivil_03/_Ato2007-2010/2007/Lei/L11502.htm > Acesso em: 25 out. 2014.

CANDAU, V. M. Magistério: construção cotidiana. Petrópolis: Vozes, 1997.

CAPES. Diretoria de Formação de Professores da Educação Básica. CAPES: Uma síntese sobre Programas de Formação de Professores da Educação Básica.

Brasília, 2013.

FREIRE, P. Política e educação. São Paulo: Cortez, 1997.

IMBERNÓN, F. Formação docente e profissional: formar-se para a mudança e a incerteza. São Paulo: Cortez, 2001.

INEP - Resultados SAEB/Prova Brasil 2011. Disponível em:

<http://sistemasprovabrasil2.inep.gov.br/resultados/> Acesso em: 25 out. 2014.

INEP - IDEB - Resultados e Metas. Disponível em:

<http://ideb.inep.gov.br/resultado/resultado/resultadoBrasil.seam> Acesso em: 25 out. 2014.

MARCELO, C. Formación de profesores para el cambio educativo. Barcelona: EUB, 1999.

NÓVOA, A. Formação contínua de professores: realidades e perspectivas. Aveiro: Universidade de Aveiro, 1991.

Os Professores na Virada do Milênio: do excesso dos discursos à pobreza das práticas. Educação e Pesquisa, São Paulo, v. 25, n. 1, p. 11-20, jan./jun. 1999.

. Novas disposições dos professores: A escola como lugar da formação. Conferência proferida no II Congresso de Educação Marista. Salvador/BA, Julho/ 2003. Disponível em: < http://repositorio.ul.pt/bitstream/10451/685/1/21205_ce.pdf> Acesso em: 25 out. 2014.

.Vidas de professores. Porto: Editora do Porto, 2000.

NÓVOA, A. Os professores e sua formação. Lisboa: Dom Quixote,1997.

RICCI, C. S. Pesquisa como ensino: textos de apoio. Propostas de trabalho. Belo Horizonte: Autêntica, 2007.

TARDIF, M. Saberes docentes e formação profissional. Rio de Janeiro: Vozes, 2002. 